\title{
Pembelajaran Literasi Digital PAUD melalui Pelatihan Tutor Paud di Pos PAUD Dahlia Kelurahan Palebon Kecamatan Pedurungan
}

\author{
Tarcisia Sri Suwarti*, Siti Lestari, Muhammad Wahyu Widiyanto
}

Pendidikan Bahasa Inggris Fakultas Pendidikan Bahasa dan Seni, Universitas PGRI Semarang, Indonesia

\author{
*Corresponding Author \\ Email: tarcisiasrisuwarti@gmail.com
}

Received:

11 September 2020
Revised:

28 November 2020
Accepted:

15 December 2020
Published:

25 December 2020

\begin{abstract}
Abstrak
Perkembangan teknologi mendukung kemajuan pendidikan di Indonesia secara signifikan. Bentuk paling sederhana dari teknologi yang sering digunakan secara digital adalah emoticon. Anak-anak usia dini pada era sekarang telah mengenal teknologi modern yang mendukung mereka untuk mengenal dunia sekitar. Sebagai contoh adalah handphone yang memiliki fitur emoticon sebagai sarana komunikasi. Oleh karena itu, para tutor Pos PAUD Dahlia Semarang perlu dibekali pembelajaran literasi digital PAUD dengan media Box Bas yang mengandung unsur emoticon untuk mengimbangi pengetahuan siswanya, sehingga meningkatkan pengetahuan pemanfaatan literasi digital bagi pembelajaran PAUD.
\end{abstract}

Kata kunci: literasi digital; tutor; PAUD

\begin{abstract}
The development of technology supports education in Indonesia significantly. The simplest form of technologies which is often used digitally is emoticon. Early young learners are recently very familiar with technology in order to know the world surround. For example, handphone which has emoticon features to show expressions. Therefore, tutors of Pos PAUD Dahlia Semarang need to be equipped with digital literacy learning through Box Bas media that contains emoticons to correspond with their students knowledge. This activity can upgrade the tutors' knowledge in teaching early young learner students by using digital literacy learning.
\end{abstract}

Keywords: digital literacy; tutor; PAUD 


\section{PENDAHULUAN}

Analisis Situasi

Pendidikan merupakan aset penting bagi kemajuan sebuah bangsa. Oleh karena itu setiap warga Negara harus dan wajib mengikuti jenjang pendidikan. Begitu pentingnya pendidikan sehingga pemerintah juga mengatur mengenai lembaga pendidikan yang paling fundamental yaitu Pendidikan Anak Usia Dini (PAUD). Pendidikan Anak Usia Dini harus dipersiapkan secara terencana dan bersifat holistik agar dimasa emas perkembangan anakmendapatkan distimulasi yang utuh, sehingga mengembangkan berbagai potensi yang dimiliki anak. Pendidikan anak usia dini merupakan pendidikan awal untuk membentuk berbagai fase perkembangan dan pertumbuhan dimana anak dirangsang dengan berbagai stimulasi pendidikan sehingga semua aspek perkembangannya berkembang optimal.

Pendidikan anak usia dini adalah bagian dari sistem pendidikan nasional yang telah diatur dalam UU RI Nomor 20 Tahun 2003 bab 1, pasal 1, butir 14 dinyatakan bahwa pendidikan anak usia dini adalah suatu upaya pembinaan yang ditujukan kepada anak sejak lahir sampai dengan usia 6 tahun yang dilakukan melalui pemberian rangsangan pendidikan untuk membantu pertumbuhan dan perkembangan jasmani dan rohani agar memiliki kesiapan dalam memasuki pendidikan selanjutnya.

Perkembangan teknologi saat ini memberikan banyak pengaruh pada masyarakat untuk berinteraksi melalui dunia maya secara luas (Pratiwi \& Pritanova, 2017; Stefany, et al, 2017). Hal ini secara nyata memberikan dampak yang signifikan dan menjadi tantangan besar dalam dunia pendidikan khususnya pendidikan anak usia dini pada era digital. Salah satu bentuk sederhana yang muncul sebagai bagian dari perkembangan teknologi dan banyak dijumpai dalam komunikasi digital adalah penggunaan emoticon. Hal ini dapat kita jumpai terutama pada penggunaan media seperti sms, e-mail, dan media komunikasi lainnya (Kurnia, et al, 2018). Emoticon berasal dari dua kata yakni Emotion dan Icon. Emoticon ini menunjukkan representasi ekspresi seseorang dalam bentuk komunikasi textual sehingga orang lain bisa mengerti kondisi seseorang saat diajak berbicara dalam bentuk text. Dalam sejarahnya, Emoticon pertama kali diciptakan tepatnya 19 September 1982 oleh Scott Fahlman di Universitas Carniegie Mellon Pennsylvania. Emoticon sangat berperan penting untuk berkomunikasi secara informal karena dapat menghilangkan sisi kesalahan interpretasi yang disebabkan kurangnya pemahaman seseorang terhadap pesan yang diterimanya.

Anak-anak usia dini pada era sekarang sedikit banyak telah mengenal berbagai teknologi modern yang mendukung mereka untuk mengenal dunia di sekitarnya, seperti media handphone dimana fitur di dalamnya juga terdapat fasilitas emoticon. Tim PKM memilih POS PAUD Dahlia Kelurahan Palebon Semarang sebagai lokasi pengabdian. Tim memilih kelurahan Palebon karena kelurahan ini merupakan salah satu lokasi KKN Universitas PGRI Semarang pada tahun 2020. Dari hasil tinjauan lapangan melalui kegiatan KKN tersebut, kami melihat bahwa tutor PAUD Dahlia masih membutuhkan pendampingan teknik mengajar PAUD yang efektif, kreatif dan menyenangkan bagi siswa dan tutor. Oleh karena itu, para tutor Pos PAUD Dahlia Semarang perlu dibekali pembelajaran literasi digital PAUD dengan media Box Bas yang mengandung unsur emoticon untuk mengimbangi pengetahuan siswanya, sehingga meningkatkan pengetahuan pemanfaatan literasi digital bagi pembelajaran PAUD.

Box Bas merupakan media pembelajaran yang berisi permainan yang mengandung emoticon yang dituangkan dalam bentuk stiker/gambar. Tim menggunakan media Box Bas untuk mengajarkan pengenalan angka, warna dan ekspresi. Kelebihan dari media Box Bas adalah media ini dibuat dengan barang-barang bekas dan bahan daur ulang serta dikemas secara sederhana dan menarik. Berdasarkan latar belakang di atas, Tim PKM Universitas PGRI Semarang memiliki solusi untuk mengatasi permasalahan lingkungan di Kelurahan Palebon, Pedurungan, Kota Semarang dengan pelatihan tutor PAUD akan meningkatkan pengetahuan pemanfaatan literasi digital untuk pembelajaran PAUD. 


\section{Permasalahan Mitra}

1. Para tutor kurang memiliki pengetahuan tentang pengajaran di PAUD dengan menggunakan literasi digital.

2. Tutor PAUD tidak memiliki media pembelajaran yang berhubungan dengan literasi digital untuk pengajaran di PAUD

3. Para tutor kurang memiliki media pembelajaran bahasa Inggris (angka, warna, dan ekspresi) dengan menggunakan bahasa Inggris yang berkaitan dengan literasi digital.

\section{Solusi dan luaran}

Solusi yang diberikan pada tutor PAUD dalam Program Kemitraan Masyarakat ini adalah sebagai berikut:

1. Pembekalan yang berisi Tentang pemahaman mengajar PAUD

2. Para tutor PAUD mendapatkan media pembelajaran (angka, warna, dan ekspresi) dengan menggunakan bahasa Inggris yang berkaitan dengan literasi digital.

3. Tutor PAUD mendapatkan media Pembelajaran bahasa Box Bas (angka, warna, dan ekspresi) dengan menggunakan bahasa Inggris yang berkaitan dengan literasi digital.

Luaran yang telah dicapai dalam program PKM ini adalah sebagai berikut:

1. Panduan Tutor PAUD dalam pengajaran dengan literasi digital

2. Media pengajaran Box Bas

\section{METODE}

1. Pelatihan

Tim Pelaksana PKM UPGRIS memberikan pelatihan kepada para tutor PAUD Dahlia Semarang tentang media pengajaran bahasa khususnya Bahasa Inggris dengan media Box Bas terhadap siswa PAUD di dalam kelas.

\section{Praktik Mengajar}

Para Tutor PAUD Dahlia Semarang mempraktikkan pengajaran Bahasa Inggris dengan menggunakan media Box Bas. Selanjutnya Tim Pelaksana memberikan pendampingan para tutor dalam menerapkan penggunaan media tersebut di dalam kelas. Hal ini dilakukan untuk memberikan bimbingan dan konsultasi yang diperlukan oleh tutor pada saat proses pelaksanaan belajar mengajar sehingga kendala maupun kesulitan yang dihadapi dapat segera teratasi dengan segera.

\section{Evaluasi Praktik Mengajar}

Kegiatan ini dilakukan bersamaan dengan pendampingan praktik mengajar pada akhir pertemuan di dalam kelas. Hal ini dimaksudkan agar tutor dapat meningkatkan kompetensi mengajarnya menjadi lebih baik dan menyenangkan baik bagi tutor maupun bagi para siswa PAUD. Tim pelaksana juga mengevaluasi sarana dan prasarana yang menghambat kegiatan proses belajar mengajar.

\section{HASIL DAN PEMBAHASAN}

\section{Hasil}

Program kemitraan masyarakat ini berlangsung dalam bentuk pelatihan. Pelatihan dilakukan selama satu bulan, satu minggu dua kali pada hari Senin dan Selasa setelah selesai kegiatan belajar mengajar (KBM) yaitu pada pukul 16.00-17.00 WIB. Pelaksanaan dilakukan dengan beberapa tahapan yaitu melalui: 


\section{Pemberian Materi Pra Pelatihan}

Tim pelaksana PKM UPGRIS memberikan materi pengajaran bahasa Inggris menggunakan media Box Bas. Materi pengajaran yang diberikan mencakup ulasan mengenai pengertian pembelajaran menggunakan literasi digital serta manfaatnya dan langkah-langkah pembelajarannya.

\section{Pelatihan}

Tahap yang dilakukan dalam pelatihan adalah pemberian apersepsi. Pada tahap ini tutor dilatih untuk memberikan ulasan tentang materi mengenai kata-kata bahasa Inggris yang diperkenalkan melalui media emoji (emoticon) berupa kepingan-kepingan yang bergambar karakter ekspresi dan media Box Bas. Media Box Bas adalah sebuah media yang dirangkai dalam bentuk papan yang berisi 5 cup berwarna merah dan 5 cup kuning yang sudah dimodifikasi dengan memotong bagian alasnya dan direkatkan pada papan. Alas yang terbuka digunakan untuk memasukkan kepingan emoji yang dissesuaikan dengan variasi tutup cup yang dapat dibuka. Tutup cup tersebut berisi petunjuk angka yang berbeda.

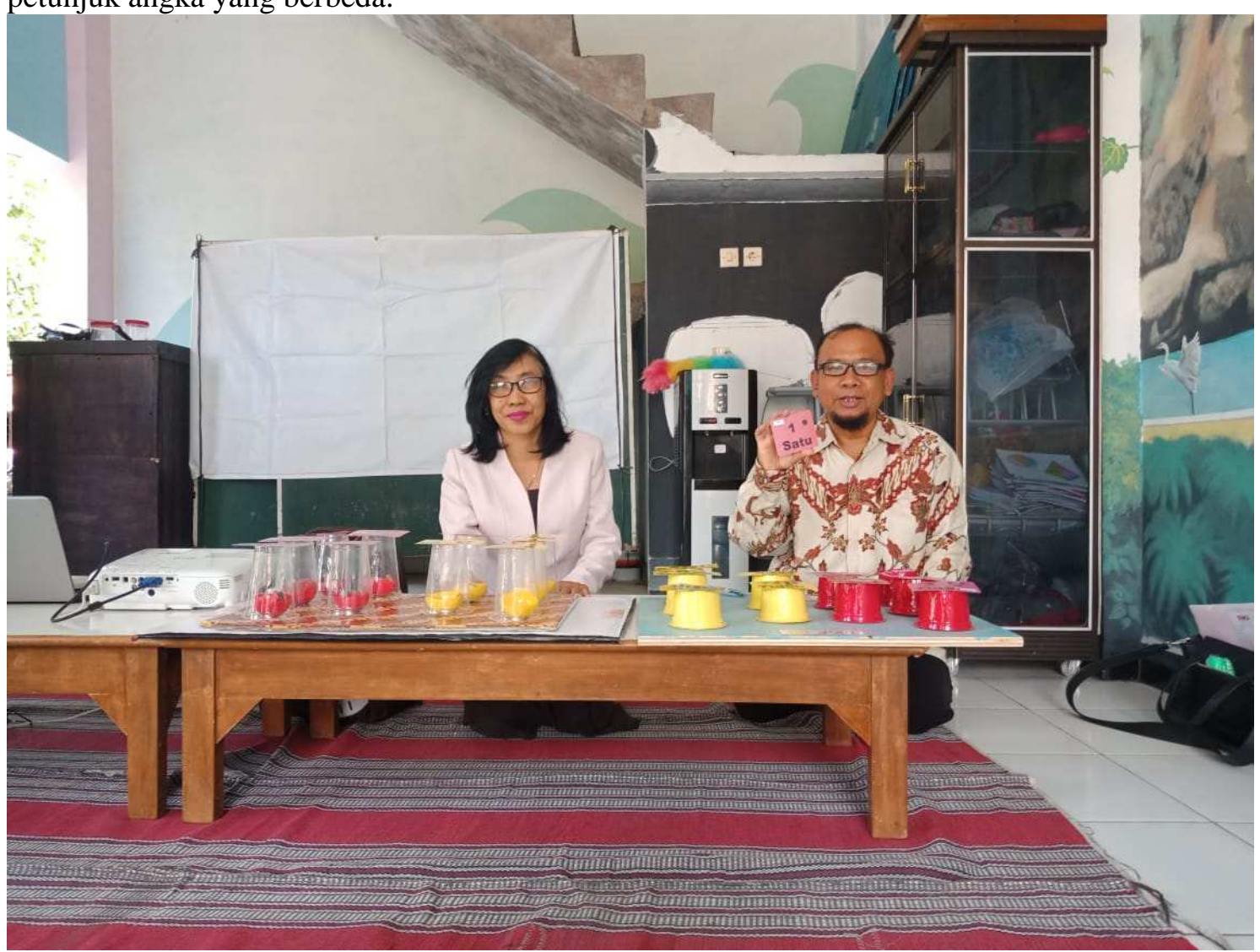

Gambar 1. Tim Pelaksana PKM sedang memberi penjelasan tentang literasi digital dan media Box Bas

Tahap selanjutnya dalam pelatihan berfokus pada kegiatan inti. Tutor diajarkan untuk mengklasifikasi kepingan emoji berdasarkan jenis karakter masing-masing. Setelah klasifikasi, tutor diarahkan untuk memasukan karakter ekspresi berdasarkan angka yang tertera pada tutup cup. 


\section{Praktik mengajar dan pendampingan}

Di dalam praktik mengajar, tutor didampingi oleh tim pelaksana PKM. Hal ini dilakukan untuk memberikan bimbingan atau konsultasi yang diperlukan oleh tutor pada saat pelaksanaan proses belajar mengajar sehingga kesulitan atau kendala segera diminimalisir. Pengajaran PAUD dilakukan 2 kali dalam seminggu.

Puncak keberhasilan kegiatan ini terletak pada $25 \%$ pelatihan dan $75 \%$ praktik mengajar. Namun pada kenyataannya, keberhasilan kegiatan pengabdian ini mencapai $90 \%$ dan dapat dikategorikan baik dan berhasil. Kegiatan ini membuat para tutor PAUD mendapatkan pemahaman tentang penggunaan media Box Bas dalam pengajaran bahasa Inggris khususnya dalam pengenalan ekspresi, warna dan angka. Box Bas merupakan media pembelajaran yang berisi permainan yang mengandung emoticon yang dituangkan dalam bentuk stiker/gambar. Kelebihan dari media Box Bas adalah media ini dibuat dengan barang-barang bekas dan bahan daur ulang serta dikemas secara sederhana dan menarik. Para tutor dapat menguasai teknik pengajaran literasi digital berbahasa Inggris dengan menggunakan media Box Bas dan dapat mengembangkan imajinasinya lebih dalam untuk pemberian petunjuk dan instruksi pada para siswanya. Kelebihan dari metode ini adalah:

1) Siswa bisa belajar bahasa Inggris dengan menggunakan karakter emoji yang sudah familiar

2) Siswa dapat langsung memahami apa yang sedang dipelajari

3) Siswa menjadi aktif dalam pembelajaran bahasa

4) Metode ini cocok untuk pengenalan kosakata

5) Suasana pembelajaran menjadi tidak tegang dan dapat menciptakan suasana pembelajaran yang positif dan menyenangkan

6) Tutor pun menjadi lebih bersemangat dan aktif mengembangkan lagi teknik mengajarnya sehingga keseluruhan pembelajaran bisa berlangsung dengan efektif.

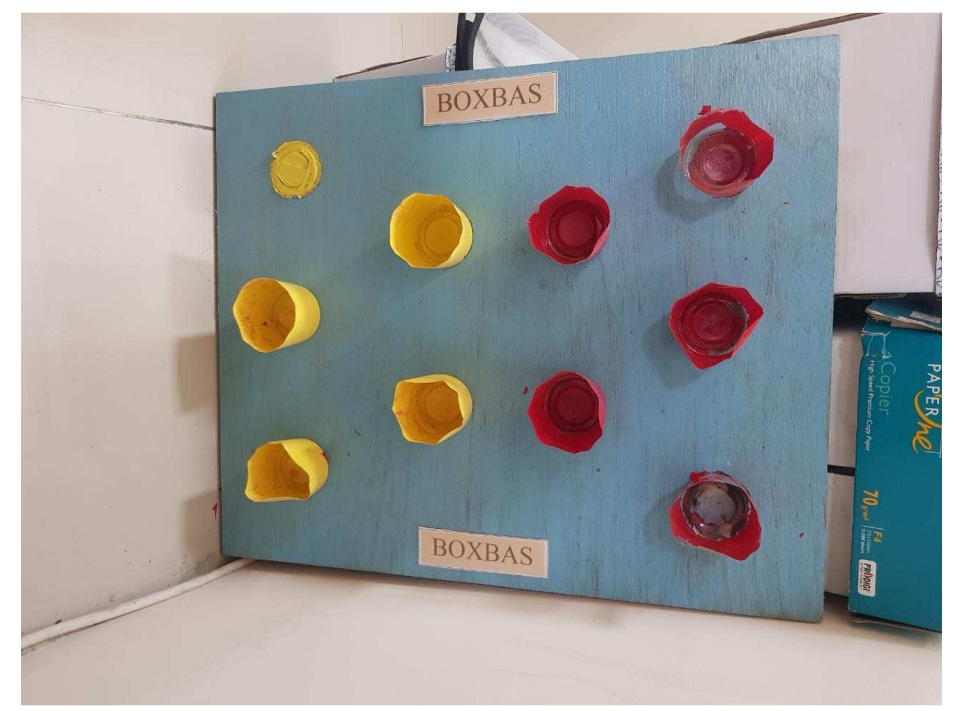

Gambar 2. Box bas (1) 


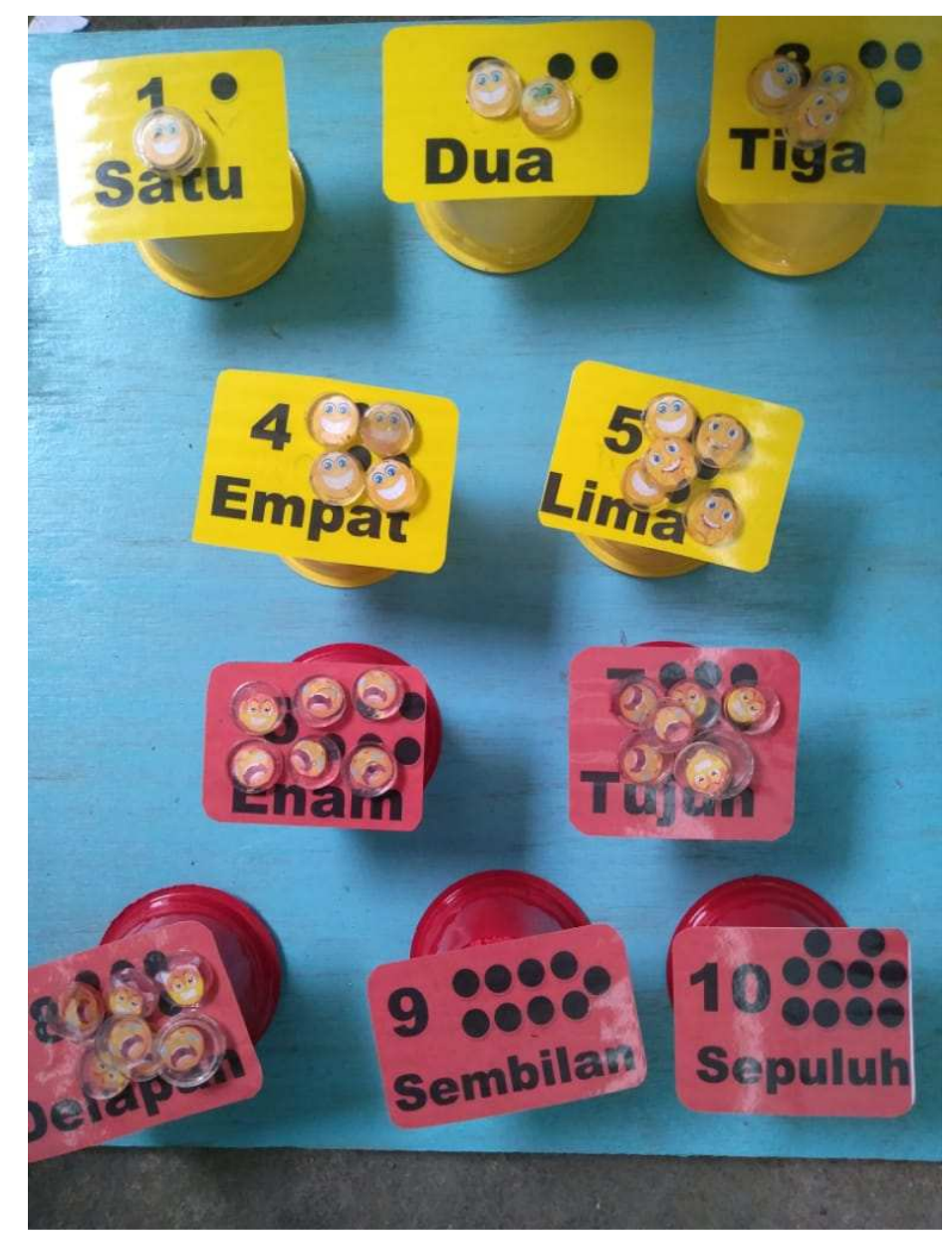

Gambar 3. Box bas (2)

\section{Evaluasi Praktik Mengajar}

Kegiatan evaluasi dilakukan pada akhir pertemuan di kelas. Dalam evaluasi yang dilakukan terdapat beberapa kendala yang sering dihadapi oleh tutor. Kendala tersebut antara lain: Kendala yang dihadapi selama pelaksanaan kegiatan pengabdian adalah bahwa pronounciation para tutor PAUD terkadang masih belum tepat dalam penyampaiannya sehingga masih perlu banyak latihan. Selain itu, durasi waktu dalam pendampingan untuk tutor masih terbatas sehingga penerapannya di kelas masih belum bisa sempurna.

\section{Pembahasan}

Tutor terlebih dahulu memperkenalkan kosakata dalam bahasa Indonesia dan bahasa Inggris kepada siswa:

1. Angka 1-10

2. Ekspresi (berupa kata sifat): senang (happy), sedih (sad) dan marah (angry)

3. Warna: merah (red), kuning (yellow) dan biru (blue).

Setelah memberikan pengenalan tersebut, Tutor memberikan instruksi pada siswa untuk mempraktikan pemahamannya pada media Box Bas. Tutor meminta siswa untuk meletakkan emoticon dengan ketentuan sebagai berikut:

1. Pin ekspresi marah diletakkan pada Box Bas merah

2. Pin ekspresi senang diletakkan pada Box Bas kuning

3. Pin ekspresi sedih diletakkan pada Box Bas biru (diluar merah dan kuning) 
4. Jumlah pin yang diletakkan tergantung dari instruksi tutor Sebagai contoh: three-happy berarti siswa harus meletakkan pin ekspresi sebanyak tiga buah pada Box Bas berwarna kuning.

5. Permainan dimainkan secara berkelompok yang masing-masing beranggotakan 5 siswa.

6. Instruksi permainan dapat diubah sesuai kreativitas tutor.

Pengajaran bahasa Inggris memang bukanlah materi yang diwajibkan dalam pengajaran PAUD. Namun alangkah baiknya bila bahasa Inggris tetap disisipkan pada materi pengajaran siswa PAUD. Teknik pengajaran harus memiliki ciri dan kriteria tertentu antara lain, memberikan pengalaman kepada siswa, memiliki ciri khas tertentu serta menarik perhatian dan mudah diikuti oleh siswa.

Keistimewaan pengajaran literasi digital berbahasa Inggris dengan menggunakan media Box Bas TPR adalah :

a. Siswa bisa belajar bahasa Inggris dengan menggunakan karakter emoji yang sudah familiar

b. Siswa dapat langsung memahami apa yang sedang dipelajari

c. Siswa menjadi aktif dalam pembelajaran bahasa

d. Metode ini cocok untuk pengenalan kosakata

e. Suasana pembelajaran menjadi tidak tegang dan dapat menciptakan suasana pembelajaran yang positif dan menyenangkan

\section{KESIMPULAN}

Kesimpulan yang didapatkan dari hasil pengabdian kepada masyarakat ini adalah bahwa tim pelaksana PKM telah menghasilkan produk berupa Panduan Tutor PAUD dalam pengajaran dengan literasi digital. Tutor PAUD Dahlia Semarang sudah mendapatkan pemahaman dan pelatihan tentang pengajaran literasi digital menggunakan media Box Bas. Selain itu, para Tutor PAUD menjadi lebih terbuka wawasannya mengenai variasi teknik pengajaran terhadap siswa PAUD.

\section{UCAPAN TERIMA KASIH}

Kami mengucapkan terima kasih yang sebesar-besarnya kepada Bapak Rektor Universitas PGRI Semarang yang telah memberikan kesempatan dan memfasilitasi pelaksanaan pengabdian kepada masyarakat dalam bentuk pemberian pelatihan pembelajaran literasi digital PAUD kepada Tutor PAUD Dahlia Semarang, Bapak Kepala Kelurahan Palebon, Kecamatan Pedurungan, Kota Semarang yang telah memberikan ijin kepada kami untuk melaksanakan kegiatan ini, Ibu-Ibu Tutor dan Calon Tutor di Pos PAUD Dahlia Semarang yang telah berperan aktif dalam kegiatan pelatihan ini, para mahasiswa yang aktif membantu pelaksanaan pengabdian masyarakat, dan para siswa PAUD yang telah antusias mengikuti kegiatan ini. 


\section{DAFTAR PUSTAKA}

Falahudin, I. (2014). Pemanfaatan media dalam pembelajaran. Jurnal Lingkar Widyaiswara, 1(4). 104-117.

Khotijah. (2016). Strategi pengembangan bahasa anak pada anak usia dini. Elementary, 2, 35-44.

Kurnia, D, N. dkk. (2018). Hubungan pemanfaatan media sosial instagram dengan kemampuan literasi media di UPT Perpustakaan Itenas. Edulib. Vol 8 (1).

Pratiwi,N., \& Pritanova,N. (2017). Pengaruh literasi digital terhadap psikologis anak dan remaja. Jurnal Semantik. Vol 6 (1). 11-24.

Stefany, S. dkk. (2017). Literasi digital dalam pembukaan diri: Studi korelasi penggunaan media sosial pada pelajar remaja di kota Medan. Sosioglobal. Vol 2 (1). 10-31.

Sujiono, Y. N. (2009). Anak usia dini. Jakarta: Gramedia.

Sulistiyo, G. (2009). Pembelajaran bilingual pada pendidikan anak usia dini. Jurnal Kajian Teori dan Praktik Kependidikan, Vol. 36 halaman 1-82.

Susanto, A. (2011). Perkembangan anak usia dini: Pengantar dalam berbagai aspeknya. Jakarta: Penerbit Kencana.

Uzer, Y. V. (2019). Strategi belajar bahasa inggris yang menyenangkan untuk pendidikan anak usia dini. PERNIK Jurnal PAUD, Vol 2 no.1 April 2019.

Villalobos-Ulate, N. 2011. Using Songs to Improve EFL Students' Pronunciation. LETRAS: 2(44), 93-108. Nacional University, Costa Rica

Yamin, M. 2010. Panduan pendidikan anak usia dini. Jakarta: Gaung Persada Press. 